\title{
Molecular surveillance of viral pathogens associated with diarrhea in pre-weaned Korean native calves
}

\author{
Ji-Hyoung Ryu ${ }^{1,2} \cdot$ Seung-Uk Shin ${ }^{1} \cdot$ Kyoung-Seong Choi ${ }^{1}$ (D) \\ Received: 14 August 2019 / Accepted: 5 December 2019 / Published online: 11 January 2020 \\ (C) Springer Nature B.V. 2019
}

\begin{abstract}
Calf diarrhea causes severe economic losses in the cattle industry worldwide. This study investigated the prevalence of bovine coronavirus $(\mathrm{BCoV})$, bovine norovirus (BNoV), bovine group A rotavirus (BoRVA), and bovine torovirus $(\mathrm{BToV})$ in calves aged $\leq 60$ days, regardless of diarrhea, across nine different regions in the Republic of Korea (ROK) and reported associations between these viruses and diarrhea. Fecal samples were collected rectally from 689 calves: normal $(n=360)$ and diarrheic $(n=329)$. $\mathrm{BNoV}(84 / 689,12.2 \%)$ was the most prevalent regardless of diarrhea, followed by BCoV $(37 / 689,5.4 \%), \mathrm{BToV}(15 / 689,2.2 \%)$, and BoRVA $(13 / 689,1.9 \%)$. Although BCoV $(P=0.032)$ and BoRVA $(P=0.007)$ were significantly associated with diarrhea in pre-weaned calves, $\mathrm{BNoV}$ and $\mathrm{BToV}$ showed no association. Infection by the four pathogens had no relationship with calf age; BoRVA was detected only in calves aged $<30$ days, but this finding was not statistically significant. Phylogenetic analysis revealed that $\mathrm{BCoV}$ isolates obtained in this study were distinct from the other known $\mathrm{BCoVs}$, and all $\mathrm{BNoV}$ isolates belonged to GIII.2 genotype; genetic variations in BNoVs are present in the ROK. BoRVA isolates distributed in the ROK were assigned to G6P[5]. Within the P[5] genotype, our isolates were divided into two lineages: P[5]-III and P[5]-VIII. P[5]- VIII lineage was dominant in pre-weaned Korean native calves. Our BToV isolates were more closely related to a European isolate, B145, than to Japanese isolates. Here, $\mathrm{BNoV}$ was frequently identified in calves, suggesting its non-significant contribution to calf diarrhea, whereas $\mathrm{BCoV}$ and BoRVA were responsible for calf diarrhea in the ROK. Consequently, our results highlight the importance of rapid diagnosis against these viruses in calf diarrhea.
\end{abstract}

Keywords Calf diarrhea $\cdot$ Bovine coronavirus $\cdot$ Bovine norovirus $\cdot$ Bovine group a rotavirus $\cdot$ Bovine torovirus

\section{Introduction}

Calf diarrhea (CD) leads to severe economic losses in livestock production worldwide owing to growth retardation and mortality of the affected young calves (Cho et al. 2013; Lyoo et al. 2018). CD can be attributed to multifactorial etiology, including various infectious agents as well as environmental and husbandry practices (Bendali et al. 1999; Meganck et al. 2015). Among numerous infectious agents causing diarrhea in

Kyoung-Seong Choi

kschoi3@knu.ac.kr

1 Department of Animal Science and Biotechnology, College of Ecology and Environmental Science, Kyungpook National University, Sangju 37224, Republic of Korea

2 Present address: Foreign Animal Disease Division, Animal and Plant Quarantine Agency, Gimcheon 39660, Republic of Korea calves, bovine coronavirus $(\mathrm{BCoV})$ and bovine rotavirus (BoRVA) are recognized as the most important viral pathogens (Athanassious et al. 1994). Moreover, bovine norovirus $(\mathrm{BNoV})$ and bovine torovirus $(\mathrm{BToV})$ are frequently associated with acute diarrhea in calves (Gebregiorgis and Tessema 2016; Mohamed et al. 2017).

$\mathrm{BCoV}$ is the causative agent for severe diarrhea in neonatal calves, winter dysentery (WD) in adult cattle, and respiratory diseases in cattle (Clark 1993; Heckert et al. 1990; Saif 1990). Enteric $\mathrm{BCoV}$ replicates in the epithelial cells of the gut and destroys the villi, thereby causing severe and often bloody diarrhea in calves; this could be life-threatening owing to the loss of electrolytes and malnutrition (Clark 1993). Disease in calves usually occurs within the first month of life. $\mathrm{BCoV}$ infection has a high morbidity but a low mortality. $\mathrm{BCoV}$ has four major structural proteins: nucleocapsid $(\mathrm{N})$, membrane (M), hemagglutinin esterase (HE), and spike (S) (Spaan et al. 1988). BCoV is divided into three genotype groups: groups 1 , 2 , and 3 depending on $\mathrm{N}$ protein gene. Variations in the host 
range and tissue tropism of coronaviruses are attributed to the spike (S) glycoprotein (Bidokhti et al. 2012).

Noroviruses are known to cause epidemic and sporadic gastroenteritis in humans and animals (Ferragut et al. 2016). Phylogenetically, noroviruses are classified into six genogroups (GI-GVI) based on RNA-dependent RNA polymerase (RdRp) and capsid gene (Pourasgari et al. 2018). GI, GII, and GIV infect humans, whereas GIII and GV infect ruminants and rodents, respectively (Thomas et al. 2014). GVI is responsible for infections in canine (Vinje 2015). BNoVs are divided into two distinct genotypes: GIII.1 and GIII.2. Both subtypes have increasingly been detected in cattle with enteric or respiratory diseases worldwide (Turan et al. 2018). BNoV was initially identified in diarrheic calves aged $<7$ days (Ando et al. 2000; Gunther and Otto 1987), but $\mathrm{BNoV}$ was subsequently found in the feces of both diarrheic and healthy animals (Di Martino et al. 2014; van der Poel et al. 2003).

Group A rotavirus (RVA), a member of the Reoviridae family, is a major pathogen associated with severe, acute gastroenteritis in various host species worldwide (Manuja et al. 2008). RVAs have 11 genome segments of double-stranded RNA encoding six structural viral proteins (VP1-VP4, VP6, and VP7) and five or six non-structural proteins (NSP1NSP6) (Estes and Cohen 1989; Pesavento et al. 2006). RVAs were classified into $\mathrm{G}$ (for glycoprotein) and $\mathrm{P}$ (for protease-sensitive) genotypes based on the two outer capsid proteins, VP7 and VP4, respectively (Matthijnssens et al. 2011). To date, based on genetic characterization, $32 \mathrm{G}$ and $47 \mathrm{P}$ genotypes have been identified in humans and animals (Dian et al. 2017). Among those, G6, G8, G10, P1, P5, and P11 were associated with most cases of diarrhea in cattle (Midgley et al. 2012).

Torovirus (ToV) is a genus belonging to the family Coronavidae, order Nidovirales (Ito et al. 2016). ToVs cause enteritis and respiratory diseases and have been identified in humans, horses, cattle, and swine worldwide. BToV, formerly called Breda virus, was first detected in the USA during an outbreak of diarrhea in calves (Woode et al. 1982). Since then, $\mathrm{BToV}$ has been established as a causative agent of diarrhea in cattle and was identified in diarrheic calves across several countries (Gulacti et al. 2014; Kirisawa et al. 2007; Park et al. 2008). The prevalence of BToV has been detected in 2.9-36.4\% of fecal samples obtained from diarrheic calves (Duckmanton et al. 1998; Park et al. 2008).

Although several studies have been conducted on the detection of viral pathogens associated with $\mathrm{CD}$ in the Republic of Korea (ROK) (Park et al. 2018; Park et al. 2007a; Park et al. 2011; Park et al. 2007b; Park et al. 2008; Ryu and Choi 2019), there is little available information about the association between diarrhea and viral pathogens. The objective of the present study was to investigate the prevalence of $\mathrm{BCoV}, \mathrm{BNoV}$, BoRVA, and BToV in calves aged 1-60 days with or without diarrhea and the relationships between calf age and viral pathogens as well as to report any associations between these pathogens and diarrhea in calves.

\section{Materials and methods}

\section{Sample collection}

A total of 689 fecal samples were collected between March 2017 and October 2018 from pre-weaned Korean native calves for $<61$ days. A veterinarian collected fecal samples rectally from individual calves. Depending on fecal condition, the obtained fecal samples were classified into normal $(n=360)$ and diarrheic $(n=329)$. Fecal samples were categorized according to age: $1-10$ days $(n=140), 11-20$ days $(n=$ 197), $21-30$ days $(n=129), 31-40$ days $(n=89), 41-50$ days $(n=79)$, and 51-60 days $(n=55)$. All samples were obtained from nine regions in the ROK. All fecal samples were placed in a 50-mL conical tube and subsequently transferred on ice in the Animal Immunology Laboratory at Kyungpook National University.

\section{RT-PCR and sequencing}

Total RNA was extracted from $200 \mu \mathrm{L}$ of fecal suspension using RNAisoPlus Reagent (Takara, Shiga, Japan) according to the manufacturer's instructions. RT-PCR was performed to amplify BCoV, BNoV, BoRVA, and BToV using the DiaStar One-Step RT-PCR Smart Mix (Solgent, ROK). PCR reaction volume was $20 \mu \mathrm{L}(10 \mu \mathrm{L}$ of $2 \times$ buffer, $1 \mu \mathrm{L}$ forward primer, $1 \mu \mathrm{L}$ reverse primer, $2 \mu \mathrm{L}$ of extracted RNA, and $6 \mu \mathrm{L}$ of RNase-free water). In negative controls, $8 \mu \mathrm{L}$ of RNase-free water without RNA was added. Nested-PCR assay for BToV was performed to increase sensitivity and specificity of amplification. Briefly, $2 \mu \mathrm{L}$ of RT-PCR product was subjected to nested PCR. PCR mixture consisted of $10 \mu \mathrm{L}$ of $2 \times$ EmeraldAmp GT Master Mix (Takara), $1 \mu \mathrm{L}$ of the nestedPCR forward primer, $1 \mu \mathrm{L}$ of the nested-PCR reverse primer, and $6 \mu \mathrm{L}$ DW. Primers used in this study are listed in Table 1. In case of BoRVA, RNA was denatured at $95^{\circ} \mathrm{C}$ for 3 min and quenched on ice. Reverse transcription was conducted at $50{ }^{\circ} \mathrm{C}$ for $30 \mathrm{~min}$; PCR activation was performed at $95{ }^{\circ} \mathrm{C}$ for $10-15 \mathrm{~min}$ followed by annealing at an appropriate temperature and time (Table 1); subsequently, extension was carried out at $72{ }^{\circ} \mathrm{C}$ for $1 \mathrm{~min}$. PCR products of nested-PCR assay were separated by gel electrophoresis on $1.5 \%$ agarose gels and visualized after staining with ethidium bromide. PCR products were purified using AccuPrep PCR Purification Kit (Bioneer, Daejeon, ROK) and subjected to direct sequencing (Macrogen, Daejeon, ROK). 
Table 1 Information of primers used in this study

\begin{tabular}{|c|c|c|c|c|c|}
\hline Virus & Target gene & Sequence $\left(5^{\prime}-3^{\prime}\right)$ & Amplicon size (bp) & Annealing temp $\left({ }^{\circ} \mathrm{C}\right)$ & Reference \\
\hline $\mathrm{BCoV}$ & Spike & $\begin{array}{l}\text { TTGTAATTTTAATATGAGCAGCC } \\
\text { TTCTGCCAACTATTATAATAAG }\end{array}$ & 951 & 50 & Tsunemitsu et al. (1999) \\
\hline $\mathrm{BNoV}$ & $\mathrm{RdRp}$ & $\begin{array}{l}\text { AGTTAYTTTTCCTTYTAYGGBGA } \\
\text { AGTGTCTCTGTCAGTCATCTTCAT }\end{array}$ & 532 & 51 & Smiley et al. (2003) \\
\hline \multirow[t]{2}{*}{ BoRVA } & VP7 & $\begin{array}{l}\text { GCCTTTAAAAGAGAGAATTTCCGTCT } \\
\text { GG } \\
\text { GGTCACATCATACAATTCTAATCTAAG }\end{array}$ & 1062 & 48 & Isegawa et al. (1993) \\
\hline & VP4 & $\begin{array}{l}\text { TTCATTATTGGGACGATTCACA } \\
\text { CAACCGCAGCTGATATATCATC }\end{array}$ & 863 & 48 & \\
\hline \multirow[t]{2}{*}{ BToV } & Spike & $\begin{array}{l}\text { GTGTTAAGTTTGTGCAAAAAT } \\
\text { TGCATGAACTCTATATGGTGT }\end{array}$ & 741 & 55 & Kirisawa et al. (2007) \\
\hline & & $\begin{array}{l}\text { TGGATTAATTCAGGAGGTGCC } \\
\text { CACTCTACATAGAGCGGTGTC }\end{array}$ & 653 & & \\
\hline
\end{tabular}

$\mathrm{BCoV}$ : bovine coronavirus, BNoV: bovine norovirus, BoRVA: bovine group A rotavirus, BToV: bovine torovirus

\section{Phylogenetic analysis}

The obtained sequence data were applied to a Basic Local Alignment Search Tool (BLAST) in the National Center for Biotechnology Information (NCBI) database for homology analyses of $\mathrm{BCoV}, \mathrm{BNoV}$, BoRVA, and $\mathrm{BToV}$ genes. The sequence identities of all viruses were verified after comparing the sequences deposited in GenBank database using the BLAST software (https://blast.ncbi.nlm.nih.gov/Blast). The sequences were aligned using ClustalX (version 1.8) program. A phylogenetic tree was constructed using the neighbor-joining method based on nucleotide alignments. Bootstrap analysis was conducted with 1000 replicates using the MEGA version 6. Nucleotide sequences of $\mathrm{BCoV}, \mathrm{BNoV}$, BoRVA, and BToV obtained in this study were deposited in the GenBank database under the accession numbers MN650885-MN650894, MN156317-MN156366, MN650895-MN650906, and MN650907-MN650917, respectively.

\section{Statistical analysis}

The PCR results for each fecal sample were recorded either as positive or negative for each pathogen and categorized according to calf age $(1-10,11-20,21-30,31-40,41-50$, or 51-60 days) and fecal consistency (normal or diarrheic feces). The data were analyzed using the SPSS Statistics 25.0 software package for Windows (SPSS, Chicago, IL, USA). The associations between diarrhea and each pathogen were calculated for all ages together and for each age group separately using Pearson's chi-squared test or Fisher's exact test, as appropriate. $P$ value of $<0.05$ was considered to be statistically significant.

\section{Results}

\section{Prevalence of viral pathogens in pre-weaned Korean native calves}

A total of 689 fecal samples collected from nine different regions were tested for $\mathrm{BCoV}, \mathrm{BNoV}, \mathrm{BoRVA}$, and $\mathrm{BToV}$ using RT-PCR. BNoV was the most prevalent viral pathogen detected in 84 calves $(12.2 \%)$ that originated from eight regions, followed by $\mathrm{BCoV}$ in 37 calves $(5.4 \%)$ from eight regions, $\mathrm{BToV}$ in 15 calves $(2.2 \%)$ from four regions, and BoRVA in 13 calves (1.9\%) from three regions (Table 2). There were differences in viral pathogens detected according to regions. All viral pathogens were identified in the Gimje region; however, at least two viral pathogens were detected across the other seven regions, except in Anseong and Sangju regions wherein only one pathogen was found (Table 2).

The association between viral pathogens and fecal consistency (normal and diarrhea) was investigated (Table 3). Based on chi-squared analysis, $\mathrm{BCoV}$ was more frequently detected in diarrheic feces $(P=0.032)$ than in normal feces. The prevalence of BoRVA was significantly associated with diarrhea $(P=$ 0.007). The detection rate of BoRVA was 5.5-fold higher in diarrheic calves than that in healthy calves. $\mathrm{BNoV}$ or $\mathrm{BToV}$ was detected in the feces of pre-weaned calves regardless of diarrhea. There was no statistically significant association between $\mathrm{BNoV}(P=0.796)$ or $\mathrm{BToV}(P=0.662)$ infection and diarrhea. As shown in Table 4, only four calves were coinfected with two viral pathogens, i.e., two calves were infected with $\mathrm{BCoV}+\mathrm{BNoV}$, one calf was infected with $\mathrm{BCoV}+\mathrm{BToV}$, and one calf was infected with $\mathrm{BNoV}+\mathrm{BToV}$. Co-infections with $\mathrm{BCoV}$ and $\mathrm{BNoV}$ were detected in one calf aged 3140 days and in another calf aged 41-50 days. Co-infection with $\mathrm{BCoV}$ and $\mathrm{BToV}$ was detected in a diarrheic calf aged 1- 
Table 2 Detection rate of viral pathogens in 689 fecal samples collected from nine different regions

\begin{tabular}{lllll}
\hline Regions & BCoV & BNoV & BoRVA & BToV \\
\hline Anseong $(n=39)$ & 0 & $4(10.3 \%)$ & 0 & 0 \\
Asan $(n=95)$ & $5(5.4 \%)$ & $12(12.7 \%)$ & $1(1.1 \%)$ & 0 \\
Geochang $(n=37)$ & $2(5.4 \%)$ & $4(10.8 \%)$ & 0 & $1(2.7 \%)$ \\
Gimje $(n=106)$ & $6(5.7 \%)$ & $2(1.9 \%)$ & $9(8.5 \%)$ & $3(2.8 \%)$ \\
Gyeongju $(n=6)$ & $3(33.3 \%)$ & $1(16.7 \%)$ & 0 & 0 \\
Mungyeong $(n=112)$ & $3(2.7 \%)$ & $19(15.6 \%)$ & 0 & $9(8.0 \%)$ \\
Samrye $(n=80)$ & $4(5.0 \%)$ & $14(17.5 \%)$ & $3(3.8 \%)$ & 0 \\
Sangju $(n=8)$ & $1(12.5 \%)$ & 0 & 0 & 0 \\
Yeoungju $(n=206)$ & $14(6.8 \%)$ & $28(13.6 \%)$ & 0 & $2(1.0) \%$ \\
Total & $37(5.4 \%)$ & $84(12.2 \%)$ & $13(1.9 \%)$ & $15(2.2 \%)$ \\
\hline
\end{tabular}

BCoV: bovine coronavirus, BNoV: bovine norovirus, BoRVA: bovine group A rotavirus, $\mathrm{BToV}$ : bovine torovirus

10 days, whereas co-infection with BNoV and BToV was detected in a healthy calf aged 1-10 days. Co-infection with viral pathogens had no association with diarrhea.

\section{Prevalence of viral pathogens depending on calf age}

The differences in the detection rates of viral pathogens according to calf age were also investigated (Table 5). Of all the viral pathogens detected, BNoV infection was the highest in calves aged 1-10 days, which gradually decreased with age; $\mathrm{BNoV}$ had a high infection rate in all age groups of preweaned Korean native calves. BCoV infections showed an even infection rate, except during 1-10 days, but the overall infection rate of $\mathrm{BCoV}$ was not higher than that of $\mathrm{BNoV}$. BoRVA infection was detected only up to the age of 30 days and was not observed in calves aged $\geq 30$ days. In preweaned Korean native calves, BoRVA infection rate was the lowest compared with the infection rate of other viral pathogens. Although BToV infection rate was high at the age of 21-30 days, it was detected in only three calves aged $\geq 30$ days. Overall, there were no statistically significant differences between calf age and viral pathogens detected in pre-weaned calves.
Table 4 Co-infections with two viral pathogens in 689 fecal samples

\begin{tabular}{llll}
\hline Variables & $\mathrm{BCoV}+\mathrm{BNoV}$ & $\mathrm{BCoV}+\mathrm{BToV}$ & $\mathrm{BNoV}+\mathrm{BToV}$ \\
\hline Fecal consistency & 1 & 0 \\
Diarrhea & 1 & 0 & 1 \\
Normal & 1 & & \\
Age (days) & & 1 & 1 \\
$1-10$ & 0 & 0 & 0 \\
$11-20$ & 0 & 0 & 0 \\
$21-30$ & 0 & 0 & 0 \\
$31-40$ & 1 & 0 & 0 \\
$41-50$ & 1 & 0 & 0 \\
$51-60$ & 0 & 1 & 1 \\
Total & 2 & 1 & \\
\hline
\end{tabular}

BCoV: bovine coronavirus, BNoV: bovine norovirus, BoRVA: bovine group A rotavirus, BToV: bovine torovirus

\section{Phylogenetic analysis of BCoV, BNoV, BoRVA, and BToV}

Of the 37 BCoV-positive amplicons, 10 good sequences were obtained and compared with the sequences of BCoV strains/ isolates, including $\mathrm{CD}$, winter dysentery (WD) as well as of respiratory $\mathrm{BCoV}(\mathrm{RBCoV})$, enteric $\mathrm{BCoV}(\mathrm{EBCoV})$, and avirulent strains. These 10 sequences showed $89.1-99.8 \%$ homology with each other. Phylogenetically, the nucleotide sequence of the $\mathrm{S}$ gene revealed no characteristic pattern of relatedness between all our isolates and the other known BCoVs (Fig. 1). Our isolates were distinct from the Korean CD and WD strains, but the HM573327 and MG518515 isolates identified from wild animals were included in the same cluster (Fig. 1).

All 84 amplicons of BNoV were sequenced, and 50 good sequences were obtained. These BNoV isolates shared 90.2$99.1 \%$ nucleotide sequence identity with each other. Nucleotide sequences detected in each farm were mostly identical, and we also included slightly different sequences depending on the region in our phylogenetic tree. Based on the partial RdRp region, all our isolates belonged to GIII.2 genotype and formed a separate clade from that of the previously detected Korean isolates (Fig. 2). The results demonstrated

Table 3 Detection rate of viral pathogens according to fecal consistency

\begin{tabular}{llll}
\hline Pathogen & $\begin{array}{l}\text { No. }(\%) \text { of positives among } \\
\text { diarrheic calves }(n=329)\end{array}$ & $\begin{array}{l}\text { No. }(\%) \text { of positives among } \\
\text { normal calves }(n=360)\end{array}$ & 0.032 \\
BCoV & $24(7.3 \%)$ & $13(3.6 \%)$ & $37(5.4 \%)$ \\
BNoV & $39(11.9 \%)$ & $45(12.5 \%)$ & 0.796 \\
BoRVA & $11(3.3 \%)$ & $2(0.6 \%)$ & 0.007 \\
BToV & $8(2.4 \%)$ & $7(1.9 \%)$ & $13(1.9 \%)$ \\
\hline
\end{tabular}

BCoV: bovine coronavirus, BNoV: bovine norovirus, BoRVA: bovine group A rotavirus, BToV: bovine torovirus 
Table 5 Prevalence of BCoV, BNoV, BoRVA, and BToV infections according to age group of calves

\begin{tabular}{lllll}
\hline Age (days) & BCoV & BNoV & BoRVA & BToV \\
\hline $1-10(n=140)$ & $10(7.1 \%)$ & $25(17.9 \%)$ & $5(3.6 \%)$ & $5(3.6 \%)$ \\
$11-20(n=197)$ & $9(4.6 \%)$ & $21(10.7 \%)$ & $5(2.5 \%)$ & $1(0.5 \%)$ \\
$21-30$ days $(n=129)$ & $7(5.4 \%)$ & $16(12.4 \%)$ & $3(2.3 \%)$ & $6(4.7 \%)$ \\
$31-40$ days $(n=89)$ & $5(5.6 \%)$ & $10(11.2 \%)$ & 0 & $1(1.1 \%)$ \\
$41-50$ days $(n=79)$ & $4(5.1 \%)$ & $9(11.4 \%)$ & 0 & $1(1.3 \%)$ \\
$51-60$ days $(n=55)$ & $2(3.6 \%)$ & $3(5.5 \%)$ & 0 & $1(1.8 \%)$ \\
$P$ value & 0.917 & 0.214 & 0.219 & 0.137 \\
Total & $37(5.4 \%)$ & $84(12.2 \%)$ & $13(1.9 \%)$ & $15(2.2 \%)$ \\
\hline
\end{tabular}

BCoV: bovine coronavirus, BNoV: bovine norovirus, BoRVA: bovine group A rotavirus, BToV: bovine torovirus

that genetic variations exist within $\mathrm{BNoVs}$ prevalent in the ROK. Our isolates were divergent from Newbury2/1976/UK and Dumfries/1994/UK.

All 13 positive samples were sequenced, and 12 BoRVA isolates were obtained. The VP7 gene of our isolates belonged to G6 genotype (data not shown). A phylogenetic analysis revealed that the VP4 gene segment of 12 isolates was clustered in the P[5] genotype (Fig. 3). The combined G and $P$ genotype of BoRVA isolates, which were distributed in the ROK regardless of diarrhea, was identified as G6P[5]. Within the $\mathrm{P}[5]$ genotype, our isolates were divided into two clades. While $11 \mathrm{P}[5]$ isolates grouped together with the strains of the $\mathrm{P}[5]-\mathrm{VIII}$ lineage, one other isolate belonged to the P[5]-III lineage in the phylogenetic tree (Fig. 3).

Of the 15 amplicons, $11 \mathrm{BToV}$ isolates were sequenced and compared with other BToV isolates/strains. Our isolates showed 98.3-99.8\% identity with each other. Phylogenetic analysis based on the partial S gene revealed that BToVs were divided into three clusters. All our BToV isolates clustered with B145 formed a separate cluster with Japanese isolates, and diverged from Croatian $\mathrm{BToV}$ isolates. $\mathrm{BNoV}$ isolates belonging to each of the three clusters were distant from the Breda 1 strain (Fig. 4).

\section{Discussion}

In this study, we investigated the prevalence of $\mathrm{BCoV}$, $\mathrm{BNoV}$, BoRVA, and BToV infections regardless of diarrhea in preweaned Korean native calves from nine different regions in
Fig. 1 Phylogenetic tree of the $\mathrm{S}$ gene of $\mathrm{CD}, \mathrm{EBCoV}, \mathrm{RBCoV}$, avirulent vaccine strains, Korean $\mathrm{CD}$ and $\mathrm{WD}$ strains, and $\mathrm{BCoV}$ strains/isolates obtained in this study. The phylogenetic tree was constructed using the neighborjoining method in MEGA6. Bootstrap values are shown at branch nodes. The Korean isolates identified in this study are indicated by a circle symbol and in bold

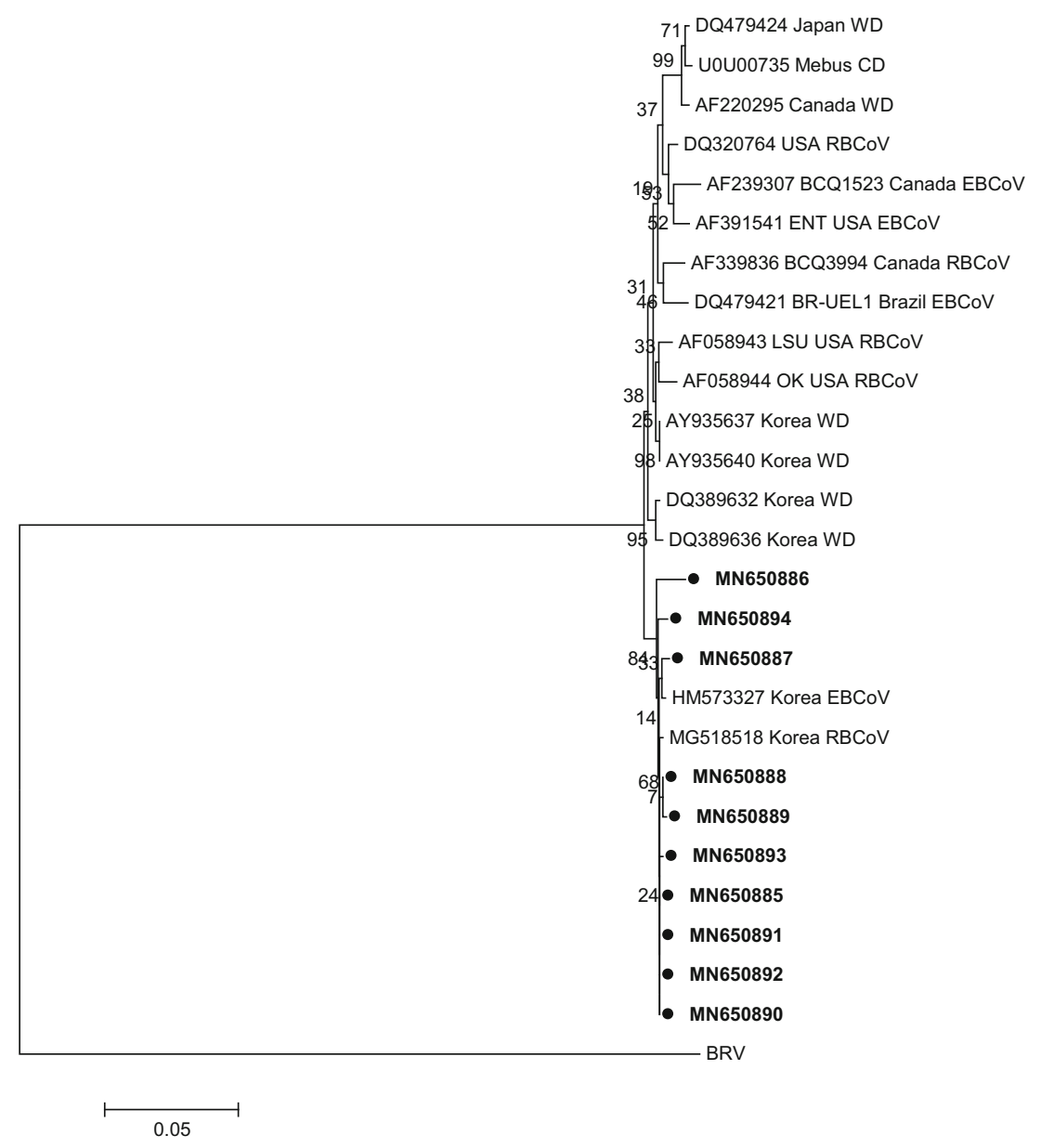


Fig. 2 Phylogenetic tree constructed based on a portion of the RdRp region (532 bp) of BNoVs using the neighborjoining method in MEGA6. Bootstrap values are shown at branch nodes. The Korean isolates identified in this study are indicated by a circle symbol and in bold

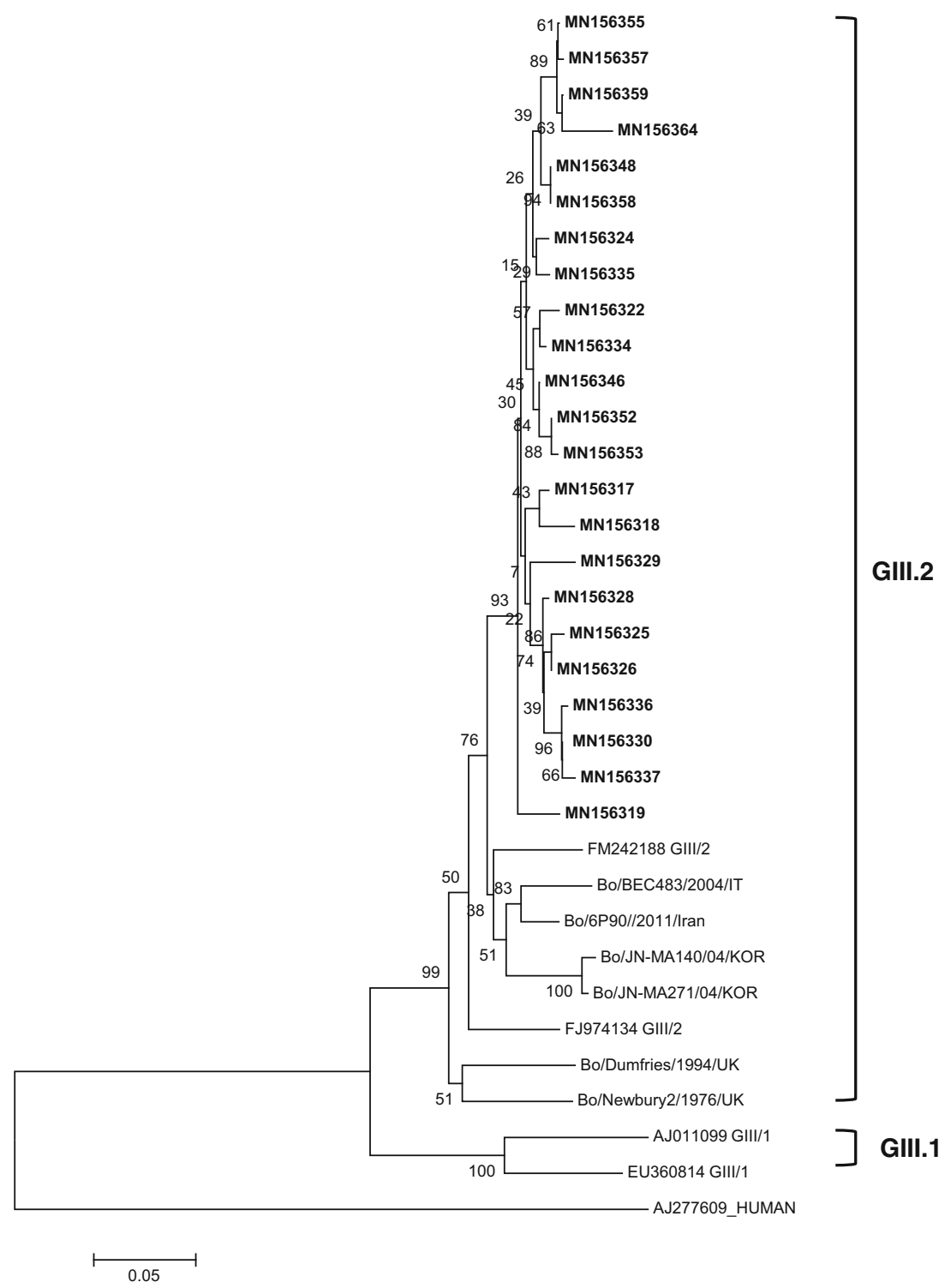

the ROK and performed genetic characterization of the identified viral pathogens. In our samples, $\mathrm{BNoV}$ was the most frequently detected pathogen; while $\mathrm{BNoV}$ and $\mathrm{BToV}$ were detected regardless of diarrhea, $\mathrm{BCoV}$ and BoRVA were mainly detected in diarrheic feces, suggesting an association with diarrhea. Moreover, the identified viral pathogens had no relationship with calf age. Our present finding that $\mathrm{BCoV}$ infection was associated with diarrhea was consistent with the result of a previous study conducted by our group (Park et al. 2018). However, the results of the present study did not reveal whether $\mathrm{BCoV}$ infection causes diarrhea in calves of only a certain age. Additionally, a possibility of the presence of other pathogens, including other bacteria, viruses, and protozoa, could not be ruled out in the fecal samples in which the abovementioned viral pathogens were not detected.

$\mathrm{BCoV}$ is considered a major viral pathogen causing $\mathrm{CD}$ (Torres-Medina et al. 1985). Here, $\mathrm{BCoV}$ was the second most prevalent viral pathogen detected in 5.4\% of all fecal samples. $\mathrm{BCoV}$ infections were found in eight of the surveyed regions, reflecting a broad distribution of $\mathrm{BCoV}$ among pre-weaned Korean native calves. Although $\mathrm{BCoV}$ is more prevalent in calves aged 1-10 days compared with the calves of other age groups, our results demonstrated no association between $\mathrm{BCoV}$ infection and calf age. Several studies have reported no association between $\mathrm{BCoV}$ infection and $\mathrm{CD}$ (Bartels et al. 2010; Uhde et al. 2008). However, the present study showed that $\mathrm{BCoV}$ infections were more commonly identified in diarrheic feces than in normal feces, indicating that $\mathrm{BCoV}$ was associated with diarrhea. A phylogenetic analysis based on the $\mathrm{S}$ gene revealed that $\mathrm{BCoV}$ isolates detected in this study diverged from $\mathrm{CD}$ and $\mathrm{WD}$ isolates reported previously in the ROK and were clustered into a separate branch. Interestingly, our isolates were more closely related to the isolates from wild animals. This suggests that genetic 
Fig. 3 Phylogenetic tree of VP4 gene with a 741-bp amplicon of the $\mathrm{P}[5]$ genotype lineage, assigned from $\mathrm{P}[5]-\mathrm{I}$ to $\mathrm{P}[5]-\mathrm{VIII}$ The tree was constructed using the neighbor-joining method in MEGA6. Bootstrap values are shown at branch nodes. The Korean isolates identified in this study are indicated by a circle symbol and in bold

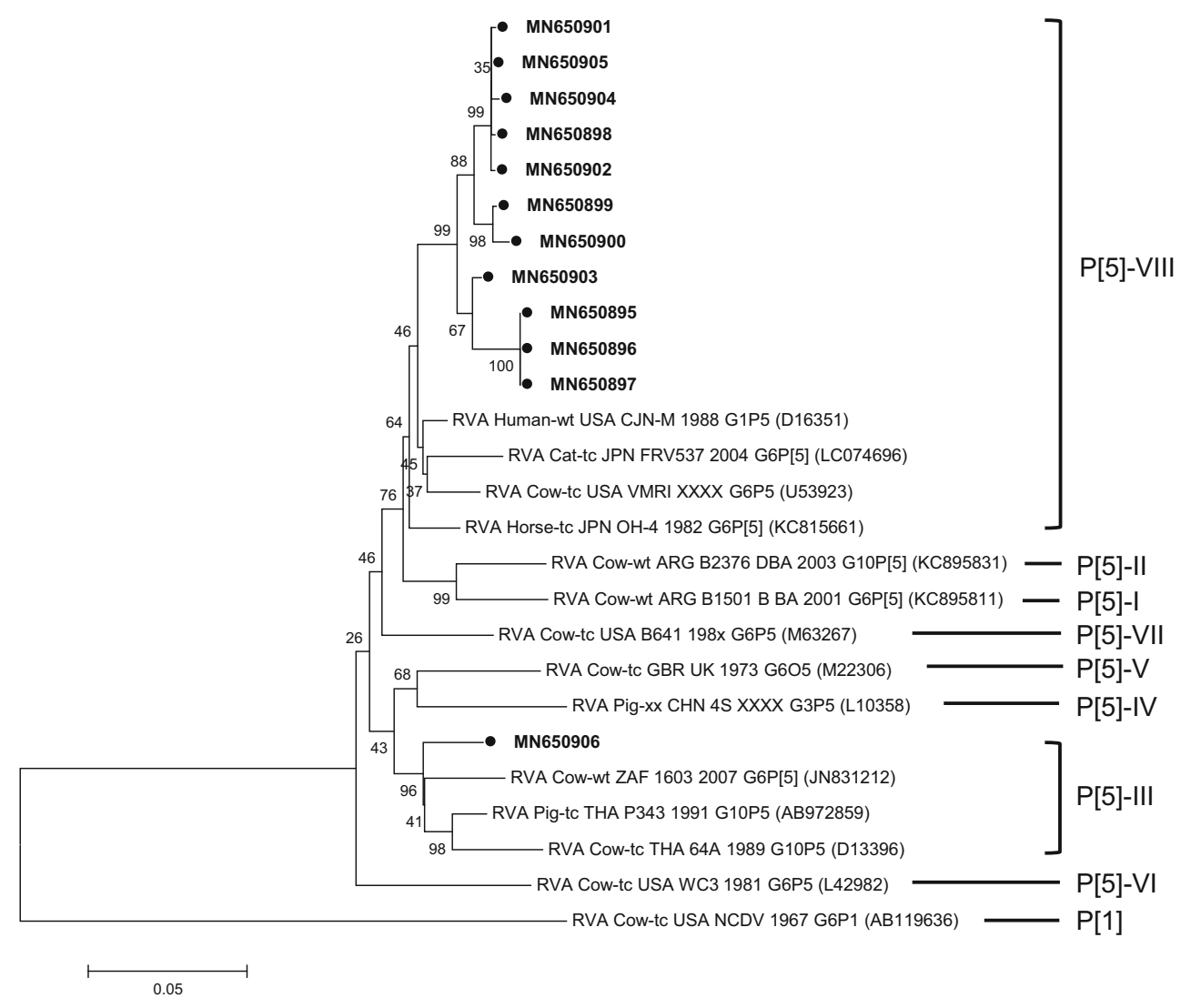

GIII.2 genotype and were divergent from the previously reported Korean isolates (Fig. 2). The results suggest that GIII.2 is the dominant genotype of BNoV circulating in the ROK, with genetic variations occurring in this strain. Further studies are warranted to investigate the pathogenicity and pathogenesis of $\mathrm{BNoV}$.

BoRVA is the primary cause of acute diarrhea in neonatal calves (Reynolds et al. 1986; Snodgrass 1986; Uhde et al. 2008). Here, the prevalence of BoRVA was considerably higher in diarrheic feces than that in normal feces. The present study revealed that BoRVA infection was significantly associated with diarrhea. BoRVA infection was observed only in calves aged $<30$ days, indicating that BoRVA causes diarrhea in young animals. Here, the prevalence of BoRVA was very low, whether the infection rate of BoRVA is originally low or whether it varies according to different groups of rotaviruses, such as group B and group C, remains unclear to date. A previous study revealed that group $\mathrm{C}$ rotavirus caused diarrhea in Korean native calves (Park et al. 2011). Another possibility is that vaccination for BoRVA has been well implemented in the ROK, which has caused a reduction in BoRVA infection rate among calves. This reflects the importance of vaccination. Several reports have indicated that the most prevalent genotypes of BoRVA are G6, G8, and G10 in combination with $\mathrm{P}$ [1], P[5], P[7], and P[11], with G6P [5] being the most prevalent in cattle among several countries (Alfieri et al. 2004; 
Fig. 4 A phylogenetic tree of the $\mathrm{S}$ gene of BToV strains/isolates and Korean isolates constructed using the neighbor-joining method in MEGA6. Bootstrap values were shown at branch nodes. The Korean isolates identified in this study are indicated by a circle symbol and in bold

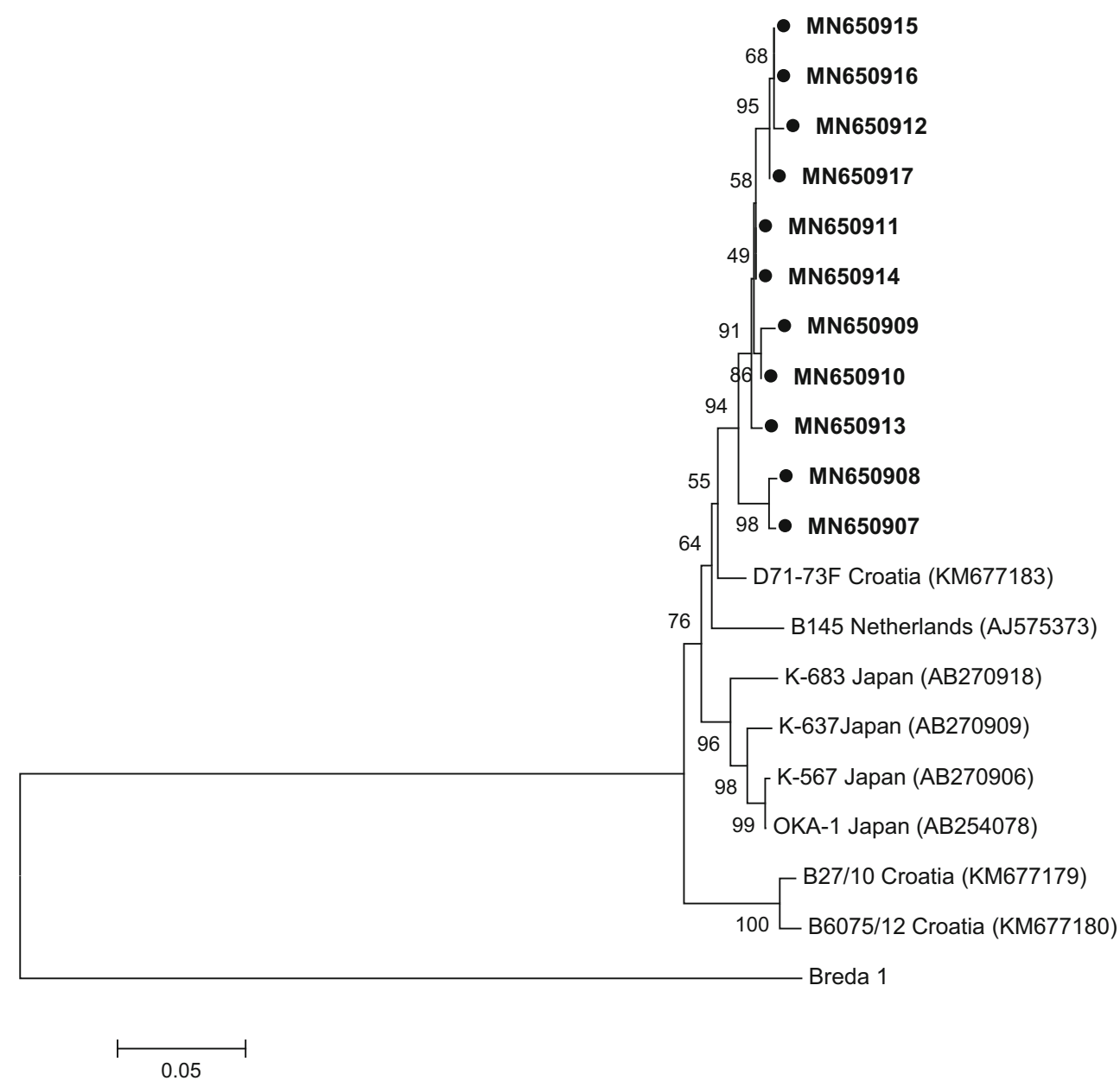

Badaracco et al. 2013; Collins et al. 2014; Fukai et al. 2004; Park et al. 2011). All our isolates detected in this study were assigned to G6P[5]. Moreover, to our knowledge, the P[5]-III and $\mathrm{P}[5]-$ VIIIlineages have been identified for the first time in the present study, and the P[5]-VIII lineage is dominant in preweaned Korean native calves. Molecular characterization of RVA strains prevalent among animals is of great importance in terms of both animal and public health. Although the prevalence of BoRVA was low in pre-weaned calves, BoRVA should be continuously surveyed to determine BoRVA genotypes circulating in Korean native calves because of interspecies transmission and reassortment events.

$\mathrm{BToV}$ was originally isolated from diarrheic calves (Lojkic et al. 2015) and is now distributed worldwide (Gulacti et al. 2014; Hoet et al. 2002; Koopmans et al. 1991; Park et al. 2008). Our results revealed that the prevalence of BToV was $2.2 \%$, which was slightly lower than that previously reported in the ROK (Park et al. 2008). This could be attributed to the different sample collection regions and the different target genes used for detecting BToV as well as calf age. BToV infection was high in Mungyeong farm compared with the other farms. The pathogens detected varied according to the farms from which samples were collected (Table 2), likely owing to the difference in hygiene levels and management systems in farms. BToV alone acts as a primary enteric pathogen in calves aged $<30$ days (Aita et al. 2012). However, our result showed that $\mathrm{BToV}$ infection was more prevalent in calves aged $\leq 30$ days, but this prevalence was not statistically significant $(P=0.137)$ and was also not associated with diarrhea $(P=0.662)$. Our findings were inconsistent with those of a previous study (Aita et al. 2012). Here, BToV was found only in co-infections with BCoVor BNoV (Table 4), and these co-infections did not cause diarrhea. To date, there is little available information regarding BToV infection causing diarrhea in the ROK. Phylogenetic analysis revealed that our isolates were more closely related to Japanese strains than to the Breda 1 strain (Fig. 4). Although BToV infection has been reported in the ROK, owing to differences in the target gene, we could not reveal genetic diversity between the isolates identified in this study and the previously reported Korean isolates. Further studies involving large-scale epidemiologic investigation of several genes are warranted to identify the prevalence of BToV and its association with diarrhea.

The results of this study revealed that $\mathrm{BNoV}$ is most frequently detected in pre-weaned Korean native calves. Of the viral pathogens examined, BCoV and BoRVA appear to be the 
major viral pathogens contributing to $\mathrm{CD}$ in the $\mathrm{ROK}$, and the prevalence of $\mathrm{BCoV}$ is higher than that of BoRVA. The prevalence of $\mathrm{BCoV}$, BNoV, BoRVA, and BToV was not significantly associated with calf age. The association of $\mathrm{BNoV}$ and $\mathrm{BToV}$ with the pathogenesis of diarrhea in pre-weaned calves remains inconclusive. Therefore, monitoring and surveillance of $\mathrm{BCoV}$ and BoRVA in cattle populations are recommended for preventing and controlling diarrhea in calves.

Acknowledgments The authors would like to thank Mr. Jeong-Byoung Chae and Du-Gyeong Han for helping to collect feces.

Funding information This research was supported by the National Research Foundation of Korea (NRF), funded by the Korea government (MSIP) (No. 2018R1D1A1B07048271).

\section{Compliance with ethical standards}

This study was approved and performed in accordance with the ethics guidelines and procedures of the policy of the review to Kyungpook National University Animal Care and Use Committee. Each farmer also provided their written informed consent prior to inclusion in our study.

Conflict of interest The authors declare that they have no conflict of interest.

\section{References}

Aita, T., Kuwabara, M., Murayama, K., Sasagawa, Y., Yabe, S., Higuchi, R., Tamura, T., Miyazaki, A., Tsunemitsu, H., 2012. Characterization of epidemic diarrhea outbreaks associated with bovine torovirus in adult cows. Archives of Virology 157, 423-431.

Alfieri, A.F., Alfieri, A.A., Barreiros, M.A., Leite, J.P., Richtzenhain, L.J., 2004. $G$ and $P$ genotypes of group A rotavirus strains circulating in calves in Brazil, 1996-1999. Veterinay Microbiology 99, 167-173.

Ando, T., Noel, J.S., Fankhauser, R.L., 2000. Genetic classification of Norwalk-like viruses. Journal of Infectious Disease 181 Suppl 2, S336-348.

Athanassious, R., Marsolais, G., Assaf, R., Dea, S., Descoteaux, J.P., Dulude, S., Montpetit, C., 1994. Detection of bovine coronavirus and type A rotavirus in neonatal calf diarrhea and winter dysentery of cattle in Quebec: evaluation of three diagnostic methods. Canadian Veterinay Journal 35, 163-169.

Badaracco, A., Garaicoechea, L., Matthijnssens, J., Louge Uriarte, E., Odeon, A., Bilbao, G., Fernandez, F., Parra, G.I., Parreno, V., 2013. Phylogenetic analyses of typical bovine rotavirus genotypes G6, G10, P[5] and P[11] circulating in Argentinean beef and dairy herds. Infection, Genetics and Evolution 18, 18-30.

Bartels, C.J., Holzhauer, M., Jorritsma, R., Swart, W.A., Lam, T.J., 2010. Prevalence, prediction and risk factors of enteropathogens in normal and non-normal faeces of young Dutch dairy calves. Preventive Veterinary Medicine 93, 162-169.

Bendali, F., Sanaa, M., Bichet, H., Schelcher, F., 1999. Risk factors associated with diarrhoea in newborn calves. Veterinary Research 30, 509-522.

Bidokhti, M.R., Traven, M., Ohlson, A., Baule, C., Hakhverdyan, M., Belak, S., Liu, L., Alenius, S., 2012. Tracing the transmission of bovine coronavirus infections in cattle herds based on $\mathrm{S}$ gene diversity. Veterinay Journal 193, 386-390.
Cho, Y.I., Han, J.I., Wang, C., Cooper, V., Schwartz, K., Engelken, T., Yoon, K.J., 2013. Case-control study of microbiological etiology associated with calf diarrhea. Veterinay Microbiology 166, 375385.

Clark, M.A., 1993. Bovine coronavirus. British Veterinay Journal 149, 51-70.

Collins, P.J., Mulherin, E., Cashman, O., Lennon, G., Gunn, L., O’Shea, H., Fanning, S., 2014. Detection and characterisation of bovine rotavirus in Ireland from 2006-2008. Irish Veterinary Journal 67, 13.

Di Martino, B., Di Profio, F., Di Felice, E., Melegari, I., Ceci, C., Mauroy, A., Thiry, E., Martella, V., Marsilio, F., 2014. Genetic heterogeneity of bovine noroviruses in Italy. Archives of Virology 159, 2717 2722.

Dian, Z., Wang, B., Fan, M., Dong, S., Feng, Y., Zhang, A.M., Liu, L., Niu, H., Li, Y., Xia, X., 2017. Completely genomic and evolutionary characteristics of human-dominant G9P[8] group A rotavirus strains in Yunnan, China. Journal of General Virology 98, 1163-1168.

Duckmanton, L., Carman, S., Nagy, E., Petric, M., 1998. Detection of bovine torovirus in fecal specimens of calves with diarrhea from Ontario farms. Journal of Clinical Microbiology 36, 1266-1270.

Estes, M.K., Cohen, J., 1989. Rotavirus gene structure and function. Microbiological Reviews 53, 410-449.

Ferragut, F., Vega, C.G., Mauroy, A., Conceicao-Neto, N., Zeller, M., Heylen, E., Uriarte, E.L., Bilbao, G., Bok, M., Matthijnssens, J., Thiry, E., Badaracco, A., Parreno, V., 2016. Molecular detection of bovine Noroviruses in Argentinean dairy calves: circulation of a tentative new genotype. Infection, Genetics and Evolution 40, $144-150$

Fukai, K., Onoda, H., Itou, T., Sato, M., Miura, Y., Sakai, T., 2004. Genetic and serological characterization of novel serotype G8 bovine group A rotavirus strains isolated in Japan. Journal of Veterinay Medical Science 66, 1413-1416.

Gebregiorgis, A., Tessema, T.S., 2016. Characterization of Escherichia coli isolated from calf diarrhea in and around Kombolcha, South Wollo, Amhara Region, Ethiopia. Tropical Animal Health and Production 48, 273-281.

Gulacti, I., Isidan, H., Sozdutmaz, I., 2014. Detection of bovine torovirus in fecal specimens from calves with diarrhea in Turkey. Archives of Virology 159, 1623-1627.

Gunther, H., Otto, P., 1987. [Diarrhea in young calves. 7. "Zackenvirus" (Jena agent 117/80) - a new diarrhea pathogen in calves]. Archiv fur Experimentelle Veterinarmedizin 41, 934-938.

Heckert, R.A., Saif, L.J., Hoblet, K.H., Agnes, A.G., 1990. A longitudinal study of bovine coronavirus enteric and respiratory infections in dairy calves in two herds in Ohio. Veterinary Microbiology 22, 187-201.

Hoet, A.E., Cho, K.O., Chang, K.O., Loerch, S.C., Wittum, T.E., Saif, L.J., 2002. Enteric and nasal shedding of bovine torovirus (Breda virus) in feedlot cattle. American Journal of Veterinary Research 63 , 342-348.

Isegawa, Y., Nakagomi, O., Nakagomi, T., Ishida, S., Uesugi, S., Ueda, S., 1993. Determination of bovine rotavirus $G$ and $P$ serotypes by polymerase chain reaction. Molecular and Cellular Probes 7, 277284.

Ito, M., Tsuchiaka, S., Naoi, Y., Otomaru, K., Sato, M., Masuda, T., Haga, K., Oka, T., Yamasato, H., Omatsu, T., Sugimura, S., Aoki, H., Furuya, T., Katayama, Y., Oba, M., Shirai, J., Katayama, K., Mizutani, T., Nagai, M., 2016. Whole genome analysis of Japanese bovine toroviruses reveals natural recombination between porcine and bovine toroviruses. Infection, Genetics and Evolution $38,90-95$.

Kirisawa, R., Takeyama, A., Koiwa, M., Iwai, H., 2007. Detection of bovine torovirus in fecal specimens of calves with diarrhea in Japan. Journal of Veterinary Medical Science 69, 471-476.

Koopmans, M., van Wuijckhuise-Sjouke, L., Schukken, Y.H., Cremers, H., Horzinek, M.C., 1991. Association of diarrhea in cattle with 
torovirus infections on farms. American Journal of Veterinary Research 52, 1769-1773.

Lojkic, I., Kresic, N., Simic, I., Bedekovic, T., 2015. Detection and molecular characterisation of bovine corona and toroviruses from Croatian cattle. BMC Veterinary Research 11, 202.

Lyoo, K.S., Jung, M.C., Yoon, S.W., Kim, H.K., Jeong, D.G., 2018. Identification of canine norovirus in dogs in South Korea. BMC Veterinary Research 14, 413

Manuja, B.K., Prasad, M., Manuja, A., Gulati, B.R., Prasad, G., 2008. A novel genomic constellation (G10P[3]) of group A rotavirus detected from buffalo calves in northern India. Virus Research 138, 36-42.

Matthijnssens, J., Ciarlet, M., McDonald, S.M., Attoui, H., Banyai, K., Brister, J.R., Buesa, J., Esona, M.D., Estes, M.K., Gentsch, J.R., Iturriza-Gomara, M., Johne, R., Kirkwood, C.D., Martella, V., Mertens, P.P., Nakagomi, O., Parreno, V., Rahman, M., Ruggeri, F.M., Saif, L.J., Santos, N., Steyer, A., Taniguchi, K., Patton, J.T., Desselberger, U., Van Ranst, M., 2011. Uniformity of rotavirus strain nomenclature proposed by the Rotavirus Classification Working Group (RCWG). Archives of Virology 156, 1397-1413.

Meganck, V., Hoflack, G., Piepers, S., Opsomer, G., 2015. Evaluation of a protocol to reduce the incidence of neonatal calf diarrhoea on dairy herds. Preventive Veterinary Medicine 118, 64-70.

Midgley, S.E., Banyai, K., Buesa, J., Halaihel, N., Hjulsager, C.K., Jakab, F., Kaplon, J., Larsen, L.E., Monini, M., Poljsak-Prijatelj, M., Pothier, P., Ruggeri, F.M., Steyer, A., Koopmans, M., Bottiger, B., 2012. Diversity and zoonotic potential of rotaviruses in swine and cattle across Europe. Veterinary Microbiology 156, 238-245.

Mohamed, F.F., Mansour, S.M.G., El-Araby, I.E., Mor, S.K., Goyal, S.M., 2017. Molecular detection of enteric viruses from diarrheic calves in Egypt. Archives of Virology 162, 129-137.

Park, S.I., Jeong, C., Kim, H.H., Park, S.H., Park, S.J., Hyun, B.H., Yang, D.K., Kim, S.K., Kang, M.I., Cho, K.O., 2007a. Molecular epidemiology of bovine noroviruses in South Korea. Veterinary Microbiology 124, 125-133.

Park, S.J., Lim, G.K., Park, S.I., Kim, H.H., Koh, H.B., Cho, K.O., 2007b. Detection and molecular characterization of calf diarrhoea bovine coronaviruses circulating in South Korea during 2004-2005. Zoonoses Public Health 54, 223-230.

Park, S.J., Oh, E.H., Park, S.I., Kim, H.H., Jeong, Y.J., Lim, G.K., Hyun, B.H., Cho, K.O., 2008. Molecular epidemiology of bovine toroviruses circulating in South Korea. Veterinary Microbiology 126, 364-371.

Park, S.I., Jeong, Y.J., Kim, H.J., Park, J.G., Kang, S.Y., Woo, S.K., Kim, C.H., Jung, C.H., Kang, M.I., Cho, K.O., 2011. Genetically diverse group $\mathrm{C}$ rotaviruses cause sporadic infection in Korean calves. Journal of Veterinary Medical Science 73, 479-482.

Park, J., Han, D.G., Kim, S., Chae, J.B., Chae, J.S., Yu, D.H., Choi, K.S., 2018. Prevalence of coronavirus from diarrheic calves in the Republic of Korea. Asian Pacific Journal of Tropical Biomedicine $8,1-6$.

Pesavento, J.B., Crawford, S.E., Estes, M.K., Prasad, B.V., 2006. Rotavirus proteins: structure and assembly. Current Topics in Microbiology and Immunology 309, 189-219.

Pourasgari, F., Kaplon, J., Sanchooli, A., Fremy, C., Karimi-Naghlani, S., Otarod, V., Ambert-Balay, K., Mojgani, N., Pothier, P., 2018.
Molecular prevalence of bovine noroviruses and neboviruses in newborn calves in Iran. Archives of Virology 163, 1271-1277.

Reynolds, D.J., Morgan, J.H., Chanter, N., Jones, P.W., Bridger, J.C., Debney, T.G., Bunch, K.J., 1986. Microbiology of calf diarrhoea in southern Britain. Veterinary Record 119, 34-39.

Ryu, J.H., Choi, K.S., 2019. Genetic analysis of bovine viral diarrhea virus in pre-weaned native Korean calves. Tropical Animal Health and Production. 2019 Apr 7. https://doi.org/10.1007/s11250-01901882-6.

Saif, L.J., 1990. A review of evidence implicating bovine coronavirus in the etiology of winter dysentery in cows: an enigma resolved? The Cornell Veterinarian 80, 303-311.

Smiley, J.R., Hoet, A.E., Tråvén, M., Tsunemitsu, H., Saif, L.J., 2003. Reverse transcription-PCR assays for detection of bovine enteric caliciviruses (BEC) and analysis of the genetic relationships among BEC and human caliciviruses Journal of Clinical Microbiology 41, 3089-3099.

Snodgrass, D.R., 1986. Evaluation of a combined rotavirus and enterotoxigenic Escherichia coli vaccine in cattle. Veterinary Record 119, $39-42$.

Spaan, W., Cavanagh, D., Horzinek, M.C., 1988. Coronaviruses: structure and genome expression. Journal of General Virology 69 (Pt 12), 2939-2952.

Thomas, C., Jung, K., Han, M.G., Hoet, A., Scheuer, K., Wang, Q., Saif, L.J., 2014. Retrospective serosurveillance of bovine norovirus (GIII.2) and nebovirus in cattle from selected feedlots and a veal calf farm in 1999 to 2001 in the United States. Archives of Virology $159,83-90$.

Torres-Medina, A., Schlafer, D.H., Mebus, C.A., 1985. Rotaviral and coronaviral diarrhea. Veterinary Clinics of North America: Food Animal Practice 1, 471-493.

Tsunemitsu, H., Smith, D.R., Saif, L.J., 1999. Experimental inoculation of adult dairy cows with bovine coronavirus and detection of coronavirus in feces by RT-PCR. Archives of Virology 144, 167-175.

Turan, T., Isidan, H., Atasoy, M.O., Irehan, B., 2018. Detection and Molecular Analysis of Bovine Enteric Norovirus and Nebovirus in Turkey. Journal of Veterinary Research 62, 129-135.

Uhde, F.L., Kaufmann, T., Sager, H., Albini, S., Zanoni, R., Schelling, E., Meylan, M., 2008. Prevalence of four enteropathogens in the faeces of young diarrhoeic dairy calves in Switzerland. Veterinary Record $163,362-366$.

van der Poel, W.H., van der Heide, R., Verschoor, F., Gelderblom, H., Vinje, J., Koopmans, M.P., 2003. Epidemiology of Norwalk-like virus infections in cattle in The Netherlands. Veterinary Microbiology 92, 297-309.

Vinje, J., 2015. Advances in laboratory methods for detection and typing of norovirus. Journal of Clinincal Microbiology 53, 373-381.

Woode, G.N., Reed, D.E., Runnels, P.L., Herrig, M.A., Hill, H.T., 1982. Studies with an unclassified virus isolated from diarrheic calves. Veterinary Microbiology 7, 221-240.

Publisher's note Springer Nature remains neutral with regard to jurisdictional claims in published maps and institutional affiliations. 